ISSN: 0514-7336 — ISSN electrónico: 2386-3943

DOI: https://doi.org/10.14201/zephyrus2021886586

\title{
LA DEMARCACIÓN DE LOS ESPACIOS DE TRÁNSITO EN LOS MILLARES (SANTA FE DE MONDÚJAR, ALMERÍA) Y SU RELACIÓN CON EL SIMBOLISMO MEGALÍTICO
}

\section{The Demarcation of Transit Spaces in Los Millares (Santa Fe de Mondújar, Almeria) and its Relation to Megalithic Symbolism}

Juan Antonio Cámara Serrano*, Alberto Dorado Alejos**, Liliana Spanedda*, Marcos Fernández Ruiz*, Julián Martínez García*, Martín Haro Navarro*, Gabriel Martínez Fernández*, Francisco Carrión Méndez* y Fernando Molina González*

* Dpto. de Prehistoria y Arqueología. Facultad de Filosofía y Letras. Universidad de Granada. Campus Universitario de Cartuja, s/n.18071 Granada.Correo-e: jacamara@ugr.es; spanedda@ugr.es; mfernandez888@hotmail.com; yulianmg3@gmail.com; mharonav@ugr.es; gabmar@ugr.es; pcarrion@ugr.es; molinag@ugr.es.ID ORCID: https:// orcid.org/0000-0003-4007-0639; https://orcid.org/0000-0003-4672-8542; https://orcid.org/0000-0003-14237749; https://orcid.org/0000-0002-1135-1610; https://orcid.org/0000-0001-9318-6040; https://orcid.org/00000002-1225-0694; https://orcid.org/0000-0002-3571-4113; https://orcid.org/0000-0002-9189-4198

** Laboratorio de Arqueometría. Dpto. de Prehistoria y Arqueología. Facultad de Filosofía y Letras. Universidad de Granada. Campus Universitario de Cartuja, s/n.18071 Granada. Correo-e: doradoalejos@ugr.es. ID ORCID: https:// orcid.org/0000-0003-0351-7550

Recepción: 3/05/2021; Revisión: 22/09/2021; Aceptación: 14/11/2021

Resumen: Recientes investigaciones en el yacimiento calcolítico de Los Millares, Santa Fe de Mondújar, Almería, han permitido reconocer diferentes representaciones figurativas asociadas a la muralla más exterior o Muralla I, construida en torno a $2900 \mathrm{cal}$ AC. La erección de esta muralla supuso una importante ampliación del poblado al ocupar zonas anteriormente destinadas a necrópolis. Se propone que algunos elementos pertenecientes al área de necrópolis fueron respetados y reutilizados para justificar, a través de los ancestros, la capacidad de acceder al asentamiento a través de la puerta principal -con la estatua-menhir situada junto a esta-, la exclusión de aquellos no vinculados -con todas las representaciones en ambos extremos de la muralla-, la integración de nuevas poblaciones -con la Tumba 63 incluida en el trazado de la muralla-, el rol de determinados personajes -con la estatua-menhir y la estela de la Tumba 63- y, en definitiva, los derechos a ocupar y explotar un territorio. Se seńala además la relación de estos procesos con los identificados tradicionalmente en las tumbas de la necrópolis.

Palabras clave: Edad del Cobre; se de la Península Ibérica; fortificaciones; necrópolis; arte megalítico; estatuas-menhir; ancestros.

AвSTRACT: Recent researches at Los Millares Chalcolithic site, Santa Fe de Mondújar, Almería, have allowed us to recognize different figurative representations associated with the outermost wall or Wall I, built around $2900 \mathrm{cal}$ BC. The erection of this wall represented an important extension of the village occupying areas previously intended for necropolis. It is proposed that some features belonging to the necropolis area were respected and 
reused in order to justify, through the ancestors, the ability to access the settlement through the main gate -with the statue-menhir placed next to the gate-, the exclusion of strangers -with all the representations at both ends of the wall-, the integration of new populations -with the Tomb 63 included in the layout of the wall-, the role of certain characters -with the statue-menhir and stela in the Tomb 63- and, ultimately, the rights to occupy and exploit a territory. The relationship of these processes with those traditionally identified in the tombs of the necropolis is also pointed out.

Key words: Copper Age; Iberian Peninsula se; Fortifications; Necropolis; Megalithic Art; Statues-menhir; Ancestors.

\section{Introducción al yacimiento de Los Millares ${ }^{1}$}

El yacimiento de Los Millares, Santa Fe de Mondújar, Almería (Fig. 1), dado a conocer a finales del s. XIX por L. Siret (1893: 33-57), está constituido por un poblado que ocupa unas 5 ha, defendido por 4 líneas de muralla concéntricas; una necrópolis aneja, que se extiende por unas 14 ha y de la que se conservan 83 tumbas, y una serie de 13 fortines en las colinas situadas al sur del asentamiento (Molina y Cámara, 2005: 32-78). Además, más allá de la línea de fortines, en las sierras de Alhama y Gádor, se ha localizado un conjunto de necrópolis y de pequeńos poblados, que debieron pasar a formar parte en un determinado momento de la formación social dominada por Los Millares, y lo mismo cabe decir de la parte occidental del Pasillo de Tabernas al noreste (Spanedda et al., 2015: 366-367) y de toda la cuenca de los ríos Andarax-Nacimiento y el cabo de Gata-Níjar (Haro et al., 2006: 323).

Las dataciones disponibles sugieren que tanto el poblado como la necrópolis se establecieron en fechas coetáneas alrededor del 3200 cal BC (Molina et al., 2020a: 36, 2020b: 74), y solo la muralla exterior -Muralla $\mathrm{I}-\mathrm{y}$ los fortines se erigieron en momentos más avanzados, en torno al 2900 cal вС

1 Este trabajo se incluye en los preparativos del Proyecto "Producción artesanal y división del trabajo en el Calcolítico del Sudeste de la Península Ibérica: un análisis a partir del registro arqueológico de Los Millares (PARTESI)" financiado por la Agencia Estatal de Investigación del Ministerio de Ciencia e Innovación (PID2020-117437GB-I00/ AEI/10.13039/501100011033) y se inscribe en la Unidad de Excelencia Archaeometrical Studies. Inside the Artefacts o Ecofacts, financiada por el Plan Propio de Investigación y Transferencia de la Univ. de Granada. la primera y, al menos, hacia $2500 \mathrm{cal}$ вс los segundos -probablemente antes si tenemos en cuenta la ausencia de dataciones para sus primeras fases de ocupación-, sufriendo un incendio general hacia 2200-2150 cal вС todos los excavados, abandonándose el poblado en esas fechas o poco después como demuestra el análisis estadístico bayesiano del conjunto de dataciones disponibles (Molina et al., 2020a: 38-42). Solo el tratamiento separado de algunas fechas puede explicar que determinados autores hayan defendido una fundación de la necrópolis más temprana (Aranda et al., 2020: 14-15) o una mayor perduración de los fortines (Lull et al., 2010: 89; Aranda et al., 2020: 15).

De hecho, respecto a la necrópolis solo la data-

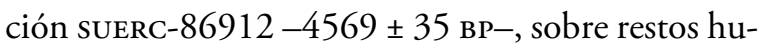
manos de la Tumba 74 (Aranda et al., 2020: 10), se separa de la cronología inicial sugerida para el conjunto (3200 cal BC), resultando unos 100 años más antigua en sus valores medios mientras los rangos 1 $\sigma$ y $2 \sigma$ de la misma integran siempre el momento de inicio propuesto. Además, otras 12 dataciones sobre restos humanos de la misma Sepultura 74 (Aranda et al., 2020: 5; Molina et al., 2020b: 70) han aportado fechas totalmente acordes a las proporcionadas por las muestras del poblado. En cuanto al final, los niveles más recientes y superficiales del poblado no han sido datados y la mayoría de las fechas publicadas de los fortines corresponden a su destrucción (Molina et al., 2020a: 38 y 41). Sin embargo, las muestras Beta-125862-4000 \pm 70 вP- у Beta-125861 -3980 $\pm 40 \mathrm{BP}-$ asociadas a los niveles de ocupación de la segunda fase del Fortín 1 han ofrecido fechas medias en torno a $2500 \mathrm{cal} \mathrm{BC}$ para esta fase. 


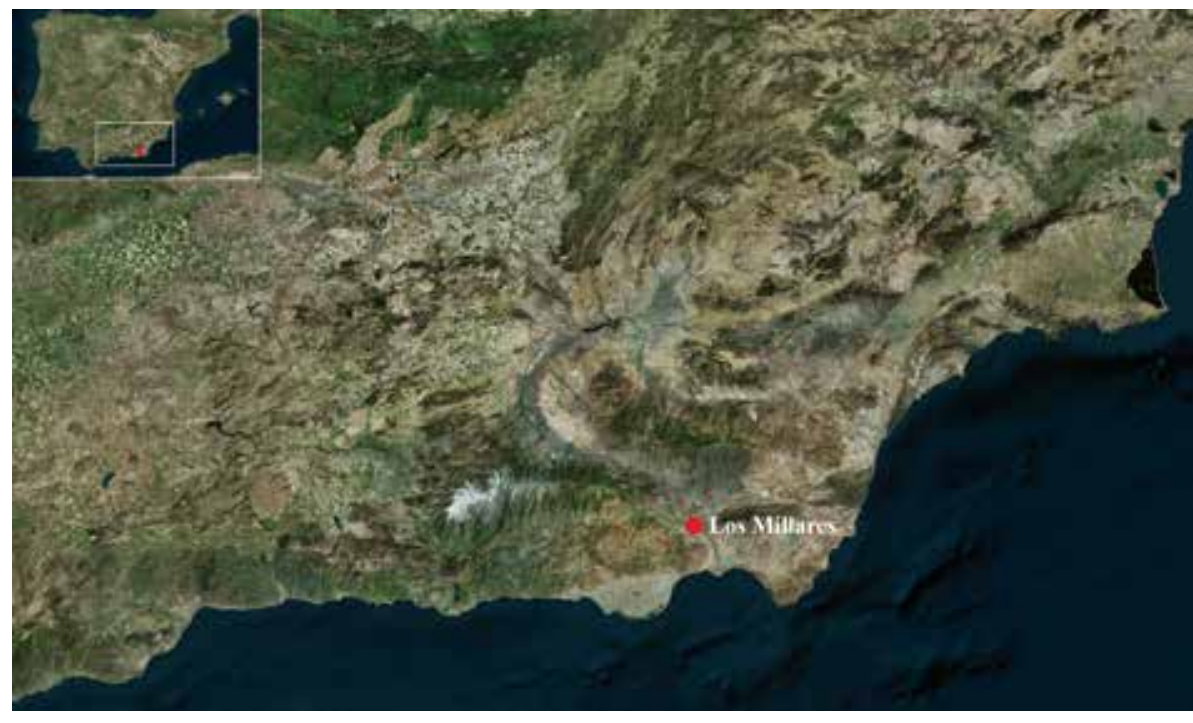

Fig. 1. Localización del poblado y necrópolis calcolitica de Los Millares (Santa Fe de Mondújar, Almeria).

\section{Objetivos y método}

El objetivo de este trabajo es indagar sobre las formas en que el ritual desarrollado en Los Millares se utilizó en el fomento de la cohesión social interna. No nos centraremos únicamente en las manifestaciones simbólicas relativas al ritual funerario, sino que abordaremos, sobre todo, el estudio de diferentes procesos relacionados con la clasificación de las personas, en particular a partir de los sistemas de representación y de segmentación del espacio en el conjunto del yacimiento, $y$, en especial, en los límites del poblado.

Pondremos especial énfasis en determinados hallazgos cuya importancia se ha valorado solo recientemente y utilizaremos, para su correcta valoración, la información obtenida a partir de técnicas de documentación gráfica de precisión. Además, tendremos en cuenta la dimensión temporal de nuestras consideraciones a partir de la asociación, más o menos directa, de las dataciones radiocarbónicas disponibles con los elementos muebles e inmuebles sobre los que se basa la discusión.

\section{Distribución, características constructivas y contenido de las tumbas de Los Millares}

El yacimiento de Los Millares siempre ha sido destacado en la bibliografía no solo por la complejidad de su sistema defensivo (Almagro y Arribas, 1963: 207-214; Molina et al., 2020a: 3137), sino también por las dimensiones de su necrópolis, por la diversidad arquitectónica de las tumbas que incluye $y$, sobre todo, por la variedad y riqueza de sus ajuares en los que están presentes numerosos objetos simbólicos y/o de prestigio (Leisner y Leisner, 1943: 17-54; Chapman, 1991: 264-267; Bueno et al., 2004: 55; Afonso et al., 2011: 307-312).

La necrópolis de Los Millares (Fig. 2) se extiende al oeste del asentamiento, en su mayor parte al exterior de la Muralla I. Sin embargo, al menos dos sepulcros se localizan al interior del circuito delimitado por esta muralla (Fig. 3a), la Tumba $17 \mathrm{y}$ la 63 -numeración de Siret, en Leisner y Leisner, 1943: 42-43, 51-52-. La explicación debe buscarse en el hecho de que la muralla más externa (I) fue construida en un momento posterior a la primera ocupación del asentamiento (Molina et al., 2020a: 41). Además de las 83 tumbas aún visibles en esta área, al otro lado de la rambla de Huéchar, frente a la zona delimitada por la Muralla IV y en línea con los Fortines 6 y 5, se encuentran los restos de, al menos, dos grandes sepulcros que deben corresponder al conjunto denominado por Siret Rambla de Huéchar (Leisner y Leisner, 1943: 54-55) y que pueden considerarse, por su ubicación y características formales, como parte integrante de la necrópolis principal aneja al asentamiento.

De hecho, al igual que estas dos, la mayor parte de las sepulturas que se localizan en la necrópolis son sepulcros de corredor con paredes de mampostería tanto en la cámara circular como en el corredor. Especialmente en las cámaras se aprecia la aproximación de hiladas que, a veces, generó una 


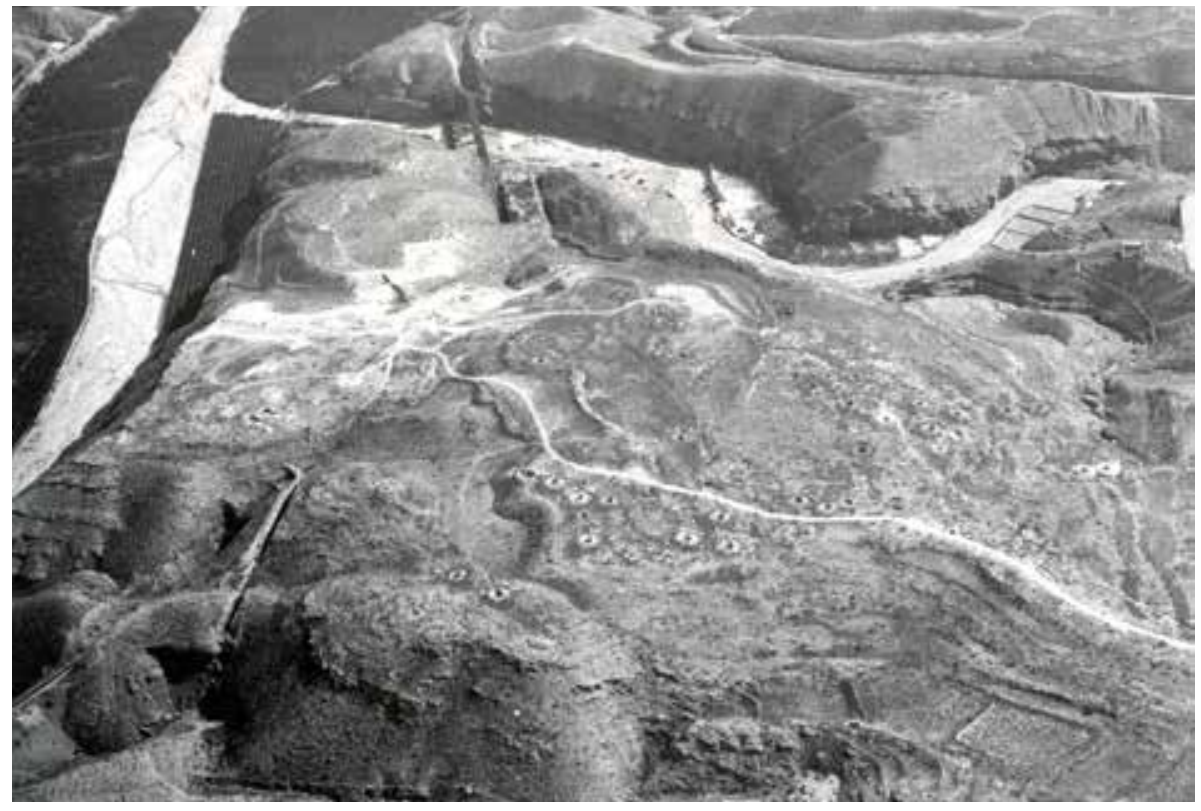

Fig. 2. Vista aérea de la necrópolis de Los Millares (Fotografia: Altair). tumbas de la necrópolis entre 2018 y 2021 y dirigidas por Haro.

Desde la cámara y el corredor se abrían nichos a los que se accedía a través de lajas de esquisto perforadas que servían de puertas. El mismo sistema de puertas perforadas separaba los diversos tramos del corredor, el paso entre este y la cámara y el acceso al corredor desde el vestíbulo.

Aun con los problemas derivados de la antigüedad de las excavaciones y del hecho de que no se excavaran de forma cubierta en falsa cúpula, más improbable en las cámaras de mayor diámetro (Blance, 1971: 52; Calvín, 2014: 5-6).

$\mathrm{Al}$ interior de las cámaras Siret localizó ciertos elementos -pilares-columnas- que, aun imitando los sistemas de sostén de las viviendas, tendrían un valor más simbólico que efectivo, habiéndose relacionado con la representación de los ancestros (Bueno et al., 2004: 55).

Tanto la cámara como el corredor presentaban revestimientos de lajas de esquisto que constituían un zócalo ortostático decorativo que acercaba simbólicamente este tipo de construcciones a los típicos dólmenes con corredor. Merece la pena señalar también la presencia de decoraciones pintadas tanto sobre los propios zócalos como sobre restos de revestimientos que debieron cubrir el alzado de las paredes. Este aspecto, mencionado por Siret (1893: 37-38) y recogido por Almagro y Arribas (1963: 166-167), no fue valorado, sin embargo, en el trabajo de Shee (1981) sobre el megalitismo decorado, aunque se ha revalorizado a partir de trabajos recientes (Bueno et al., 2004: 55) y confirmado tras las actuaciones de conservación realizadas sobre algunas exhaustiva algunos sepulcros -especialmente aquellos con pocos restos de ajuar-, es indudable que las tumbas fueron verdaderos osarios colectivos, conteniendo entre la veintena y el centenar de cadáveres (Leisner y Leisner, 1943: 17-54), utilizados durante generaciones (Aranda et al., 2020: 14; Molina et al., 2020b: 74-75).

Aunque el carácter fragmentario de los restos conservados en el Museo Arqueológico Nacional (Peña, 2011: 78) dificulta las estimaciones, parece que, como en otras regiones peninsulares (Waterman y Thomas, 2011: 171-172; Beck, 2016: 64-69; Cámara et al., 2016b: 162-168), los restos mortales de mujeres y niños también formaron parte habitualmente del ritual funerario normalizado y, por tanto, tuvieron un rol en la justificación del orden social.

En relación con el análisis de la jerarquización social, el carácter de las intervenciones arqueológicas y el mismo tratamiento reservado a los difuntos y a las ofrendas en el ritual colectivo, con frecuentes manipulaciones y traslados, hace difícil evaluar, a partir de los contenidos de las tumbas, posibles diferencias sociales, impidiéndonos adscribir elementos concretos a individuos particulares (Cámara et al., 2018: 53). La solución adoptada en los diferentes estudios ha sido comparar los contenidos de las 
J. A. Cámara Serrano, A. Dorado Alejos, L. Spanedda et al. / La demarcación de los espacios de tránsito en Los Millares (Santa Fe de Mondújar, Almería) y su relación con el simbolismo megalítico
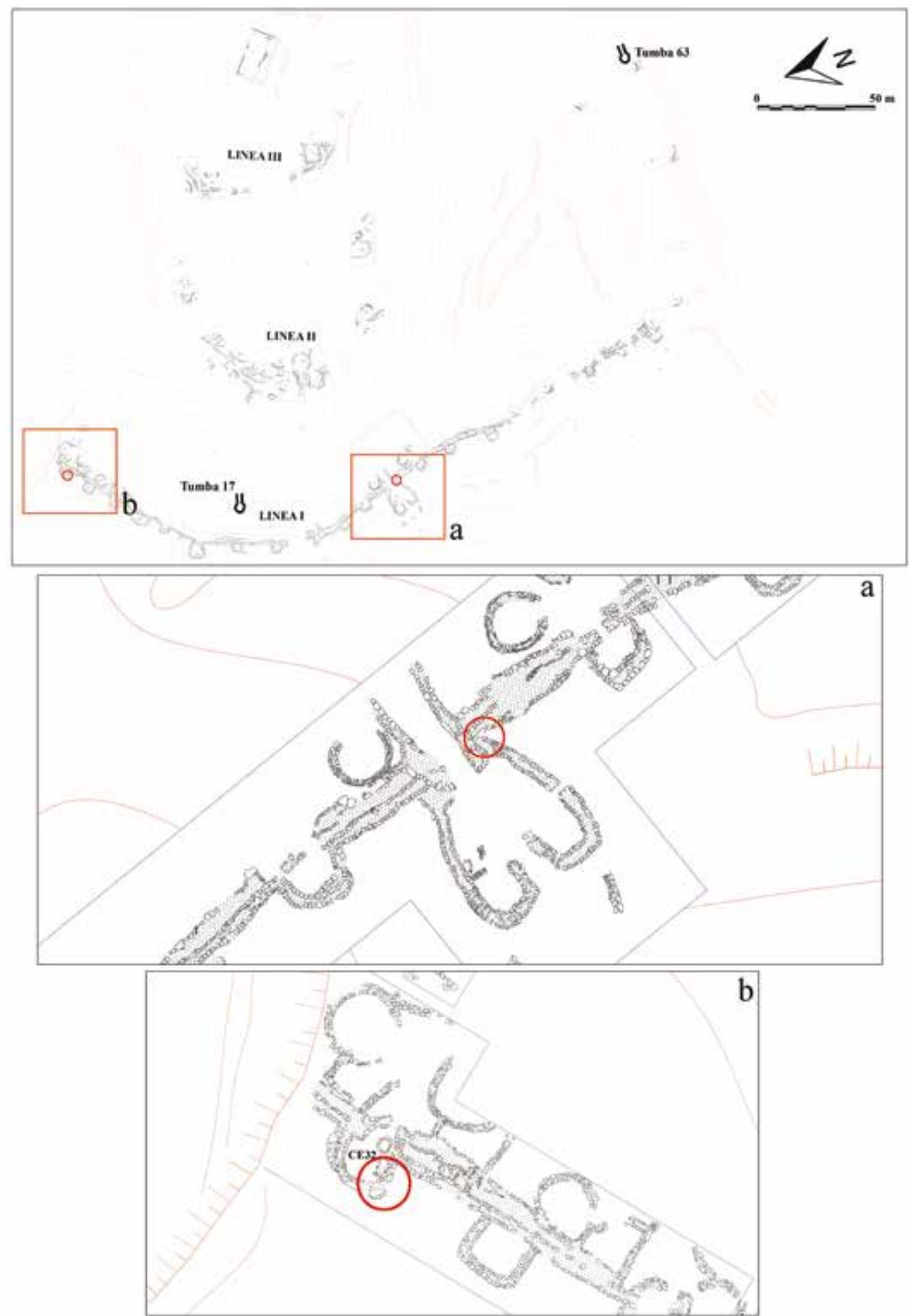

Fig. 3. Planimetría del poblado de Los Millares con indicación de las representaciones figuradas que se analizan en el presente estudio: a) localización de las diversas áreas; b) estatua-menhir en el CE6 o 'barbacana'; c) fragmentos de estatua-menhir en la torre CE32. 
diversas sepulturas tratando cada una de ellas como una unidad (Chapman, 1991: 264-267; Molina y Cámara, 2005: 60-62; Afonso et al., 2011: 307312). Las concentraciones/ausencias en algunas tumbas de ciertos elementos exóticos o considerados de prestigio o indicadores del ejercicio del poder o la violencia/agresión - puntas de flecha y puñales de sílex, armas de metal, cerámica decorada, vasos de piedra, ídolos, objetos en marfil, fragmentos de huevos de avestruz decorados, etc.- parecen mostrar diferencias sustanciales. Más significativo es el hecho de que precisamente el número de objetos en cada tumba, sobre todo de aquellos que se consideran de especial relevancia simbólica, no suele tener relación con el número de cadáveres, sugiriendo que no todos los individuos depositados en cada sepulcro tuvieron la misma categoría social. Además, se puede mantener que no todos los grupos sociales tuvieron la misma capacidad de movilizar fuerza de trabajo, de agruparla en la vida y en la muerte y, por tanto, de acumular riqueza y justificar el poder (Cámara et al., 2018: 66).

También el número de ídolos al interior de los sepulcros y de betilos al exterior de estos reflejaría estos procesos, si mantenemos su identificación con los inhumados y, en definitiva, con los ancestros.

Otros aspectos que, en nuestra opinión, tienen relación con la justificación ideológica del poder se aprecian a partir de los tipos de tumbas minoritarios, en cueva o en dolmen de cámara trapezoidal. Como ejemplifica la ya referida Tumba 63, el ajuar de estos sepulcros, aun mostrando rasgos arcaizantes y difiriendo significativamente del de los sepulcros de corredor en mampostería, está lejos de poder ser considerado 'escaso' en todos los casos. En este sentido, se ha considerado que mostrarían el derecho de grupos sociales destacados procedentes de poblaciones asimiladas, o sometidas, a ser enterrados en la necrópolis de Los Millares (Molina y Cámara, 2005: 80), aspecto que debió tener lugar en un momento anterior a $2900 \mathrm{cal} \mathrm{вС} \mathrm{como} \mathrm{mos-}$ traría la integración del Sepulcro 63 en el trazado de la Muralla I.

La utilización de recursos propios de los sepulcros de corredor en mampostería, como las puertas perforadas en esquisto, en las tumbas megalíticas de

Ediciones Universidad de Salamanca / 요 las colinas de Alhama y Gádor, apuntaría en la misma dirección.

\section{La demarcación de las zonas de tránsito y la clasificación a través de la posición y la figuración de los ancestros}

\subsection{Compartimentaciones y representaciones figuradas en las sepulturas}

La importancia en las tumbas de Los Millares de la separación de diferentes zonas -cámara, corredor, nichos en ambos, vestíbulo, recintos exteriores...-y la segmentación de algunas de ellas -los corredoresa partir de la presencia de compartimentaciones, frecuentemente en la forma de puertas de esquisto perforadas, ha sido referida de forma habitual (Siret, 1893: 37-38; Leisner y Leisner, 1943: 17-54; Almagro y Arribas, 1963: 167-168; Molina y Cámara, 2005: 53-54) y se ha vinculado con procesos de clasificación y diferenciación de los inhumados (Chapman, 1991: 253-254) y diferentes fases de culto a los ancestros (Cámara et al., 2018: 63).

En relación con estas compartimentaciones, se ha referido también la existencia de estelas más o menos antropomorfas situadas, como en otros sepulcros megalíticos de Europa occidental, en espacios específicos, como en las entradas a las diferentes zonas o en la cámara en línea con los accesos, considerándose como representaciones de los ancestros también los presuntos elementos de sostén simbólicos (Bueno et al., 2004: 34; 2015: 447). Todos estos objetos deben relacionarse con otras manifestaciones simbólicas como estatuillas de diferentes formas -betilos, ídolos tolva, ídolos falange, ídolos antropomorfos...-y realizadas en distintos materiales (piedra, hueso...) que se han vinculado al culto a los ancestros, pero también a ritos de fertilidad y de justificación del dominio de los hombres sobre las mujeres y al desarrollo de cultos a divinidades (Escoriza, 1991-92: 152-153; Martínez y Afonso, 2003: 96-97; Martínez y López, 2020: 71, 73, 77, 80-81).

$\mathrm{Si}$ aceptamos la relación de ciertos tipos, como los ídolos falange o los ídolos tolva, con la fertilidad y, por tanto, con las mujeres, se podría destacar su concentración en el interior de las tumbas, junto 
a los huesos de los ancestros, funcionando como amuletos o representaciones de una parte de estos y una propiedad característica de una sección de la población, la femenina, esto es, la reproducción.

Por otro lado, la posición de las estelas en las tumbas podría vincular estas representaciones, como se ha propuesto (Bueno y Balbín, 2006: 40, 48; Bueno et al., 2014: 11; 2015: 451-452), con la reproducción del poder, desde el que se clasifica y se explota a las personas, de la misma forma que se ordenan los restos de sus ancestros en las tumbas.

$\mathrm{Al}$ exterior de las sepulturas, el culto de los ancestros genéricos -impersonales y asexuados- se manifestaría en los betilos troncocónicos mientras el uso de reliquias óseas y de representaciones más naturalistas en las viviendas u otros espacios no funerarios, así como las decoraciones de objetos cerámicos -cerámica simbólica-, podrían sugerir un intento de vinculación a antepasados más concretos, especialmente en zonas particulares donde esos objetos parecen concentrarse, como las estatuillas en los Fortines 1 y 5 o en las proximidades de la $\mathrm{Mu}$ ralla I (Arribas et al., 1981: 103; Molina y Cámara, 2005: 54, 75, 94-96; Martínez y López, 2020: 74, 78-79) y la cerámica campaniforme al interior de la Muralla Iv (Arribas y Molina, 1987: 136; Martínez y Afonso, 2003: 96).

\subsection{La puerta central (CEG) de la Muralla I de Los Millares}

La misma conformación del asentamiento, a partir de las 4 murallas que lo defienden, supone una estructura de segmentación que puede considerarse también relacionada con diferencias sociales -y clasificación- y con distintos usos del espacio (Molina y Cámara, 2005: 20-24; Castro et al., 2010: 146-149), como atestiguan además las diferencias en consumo de carne (Navas et al., 2008: 337-338) o la ya referida concentración de cerámica campaniforme al interior de la Muralla IV (Arribas y Molina, 1987: 136; Martínez y Afonso, 2003: 96). La necrópolis y, sobre todo, los fortines pueden considerarse parte de ese mismo sistema de defensa/separación/segregación que, más allá de su

Ediciones Universidad de Salamanca / 요요 manifestación simbólica y justificadora, indudablemente, tiene implicaciones coercitivas y de ostentación (Molina y Cámara, 2005: 74).

En este sentido, los espacios de tránsito, las puertas, adquieren una importancia fundamental y se ha referido (Cámara et al., 2016a: 96-97) el interés que las personas que residieron en Los Millares pusieron en conseguir -y mejorar- sistemas de acceso fácilmente defendibles. Más allá de ello, sin embargo, la puerta central de Los Millares en la Muralla i ofrece una serie de rasgos que la conectan con los sistemas de demarcación simbólica empleados en las sepulturas del mismo yacimiento.

La complejidad de la puerta central -Ce6- de la muralla externa se reveló a lo largo de las campañas de excavación que la afectaron (Arribas et al., 1981: 96-97). Según la interpretación de la secuencia constructiva deducida a partir de esas excavaciones, el acceso en un primer momento fue un simple y amplio vano en el trazado de la muralla de unos 4,50 $\mathrm{m}$ de anchura. Al igual que los espacios de umbral de las sepulturas, esa abertura estaba monumentalizada mediante dos grandes jambas que se situaban a ambos lados de la abertura y que debieron preceder el verdadero cierre, la puerta en madera. Uno de los dos grandes ortostatos que actuaron como jambas apareció en posición mientras para el otro, aun estando caído, se pudo precisar su posición (Figs. 3b, 4a, 4b) gracias también a la documentación de las excavaciones de los años $50 \mathrm{del}$ s. Xx (Almagro y Arribas, 1963: lám. Ix).

Estas piedras destacan, entre el resto de la construcción, por su tamaño y por su apoyo sobre el lado más corto, como los ortostatos en las construcciones megalíticas, aspecto que es raro en el resto de las estructuras defensivas de Los Millares, donde solo en el extremo norte de la misma muralla externa aparecen ortostatos a modo de base ciclópea (Molina y Cámara, 2005: 55), no siendo esta, como veremos, la única coincidencia.

Gracias a que se ha podido observar que las primeras modificaciones en esta zona de la muralla exterior implicaron solo adosamientos internos al cuerpo original del muro (Arribas et al., 1981: 96), cabe pensar que no se consideró que la seguridad

Zephyrus, LXXXVIII, julio-diciembre 2021, 65-86 
del poblado estuviera comprometida por la existencia de esa amplia entrada monumental, manteniéndose esa disposición durante un largo periodo de tiempo. En cualquier caso, los refuerzos internos aumentaron el grosor de la muralla hasta los $3 \mathrm{~m}$, lo que, sin duda, facilitaría la disposición de un amplio adarve superior con estructuras de madera apoyadas en construcciones de barro. Antes de la configuración de este adarve, la defensa de la puerta desde los laterales y desde una posición elevada solo era factible desde las torres cercanas, situadas a distancias regulares como se ha demostrado (Esquivel y Navas, 2007: 899-901).

La integración del acceso en un pasillo alargado hacia el interior y, sobre todo, la construcción de dos nuevos cuerpos de mampostería, que alargan el paso por la puerta en una prolongación de 1,70 m hacia el exterior sí debieron de implicar un cambio significativo en la percepción de la entrada, aunque las jambas ortostáticas siguieron formando parte del sistema. Sin embargo, su percepción desde el exterior desapareció totalmente. La construcción de un pasillo hacia el interior, del que se han conservado $10 \mathrm{~m}$ de longitud, debió incidir en la pérdida del significado simbólico de demarcación del área de transición, aun cuando el tránsito seguía estando marcado, implicando más etapas y dificultades, que incrementaban además la eficiencia defensiva.

En este nuevo sistema que se puede colocar en la transición entre Cobre Pleno y Reciente, hacia 2600 cal BC, la única referencia de demarcación externa que pervive del sistema original como elemento visible es la estatua-menhir situada a la derecha de la entrada y cuyo análisis constituye la parte central de este trabajo (Fig. 3b). Dicha estatua-menhir, sin embargo, resultó parcialmente oculta (Fig. 4b), quedando su significado y propósito originarios supeditados a las nuevas necesidades defensivas, cuando se construyó la parte más monumental de la puerta principal de Los Millares, en torno a 2500 cal AC, la defensa en 'tenaza' o 'barbacana'.

Esta construcción, avanzando incluso sobre los límites del foso, permitía, con la ayuda de las torres y el adarve sobre la muralla, hostigar a los asaltantes desde diferentes ángulos evitando que se acercaran en demasía a la puerta, añadiendo además otro

Ediciones Universidad de Salamanca / 요 cierre en el frente a los ya existentes entre la muralla y el pasillo hacia el interior. Aun con la ocultación de ciertos elementos de la disposición original del ingreso, el mensaje ideológico pervivió en cierta medida puesto que la nueva defensa en 'tenaza' no solo era más eficiente, sino que expresaba aún más el poder de los habitantes del poblado de Los Millares. En cualquier caso, como en el resto de accesos documentados en las excavaciones - puerta sur de la Muralla I, puerta central de la Muralla II y puertas de los Fortines 1 y 5, por ejemplo-, la modificación estuvo dirigida fundamentalmente por necesidades defensivas, aun continuando e incrementando la monumentalidad y la capacidad de clasificación de los transeúntes.

Otras construcciones situadas sobre el foso al exterior de la 'barbacana' debieron servir de apoyo para los sistemas removibles de madera que podían ser retirados en caso de conflicto. En este sentido, posiblemente existieron desde el comienzo de la vida de la Muralla I, pero debieron experimentar modificaciones, en especial con la construcción de la barbacana. Las denominadas saeteras pudieron haber sido usadas también para evitar que los asaltantes emplazaran dispositivos destinados a salvar el obstáculo del foso.

\section{Las representaciones figuradas en la muralla exterior de Los Millares}

\subsection{Sistema de documentación}

Para contribuir a los aspectos discutidos en este trabajo, se ha realizado la documentación de todos los elementos grabados localizados sobre diversos soportes incorporados a la construcción de la $\mathrm{Mu}$ ralla I de Los Millares. Para ello se han utilizado técnicas de fotografía digital y se ha procedido a la realización de calcos indirectos, con su respectivo tratamiento informático y análisis 3D. Los calcos definitivos reflejan todos los motivos registrados, más de un centenar, así como los principales accidentes de las superficies de los soportes.

Para realizar la documentación fotogramétrica (Cosmas et al., 2003: 166-174; McCarthy, 2014: 
176-177; Remondino, 2014: 18-20)2 , hemos tenido que adaptarnos a difíciles condiciones de iluminación, con fuertes contrastes entre luz y sombra. Además de un amplio número de fotografías generales, las fotografías de detalle se han realizado con cámaras Canon Power Shot sx430 Is, en la opción macro y con una sensibilidad Iso automática. A continuación, se emplearon programas de edición fotográfica para seleccionar únicamente cada una de las partes objeto de análisis. A través de programas como Adobe Photoshop (C) se generaron máscaras de capa individuales, imprescindibles a la hora de agilizar el proceso fotogramétrico posterior u obtener réplicas 3D precisas. Por otro lado, la utilización de programas de tratamiento de imágenes y digitalización vectorial, como DStretch y $\mathrm{Au}$ tocad, nos permitió una mejor identificación de los motivos. En concreto, los modelos 3D han sido generados de forma semiautomática a partir de Agisoft Metashape y correctamente escalados y orientados se han exportado a formatos .obj y .ply con el objetivo de maximizar su compatibilidad. Seguidamente pasamos a contextualizar y describir los tres elementos que presentan motivos incisos.

\subsection{La estatua-menhir de la Muralla I de Los Millares}

\subsubsection{Ubicación}

Como hemos dicho, esta estatua-menhir se localiza a la derecha de la puerta principal -CE6- de la muralla exterior de Los Millares (Figs. 3b y 5a). La ocultación de la misma por la realización final de la defensa en 'tenaza' ha dificultado su identificación, aunque fuera visible desde el mismo momento de la excavación de la zona (Fig. 4b).

2 También Maldonado, A.: La aplicación de la fotogrametría (SFM) y las nuevas tecnologías para la mejora de la documentación, difusión y divulgación del Patrimonio Arqueológico. Tesis doctoral presentada en 2020 en la Univ. de Granada, pp. 72-109 (http:// hdl.handle.net/10481/62261).

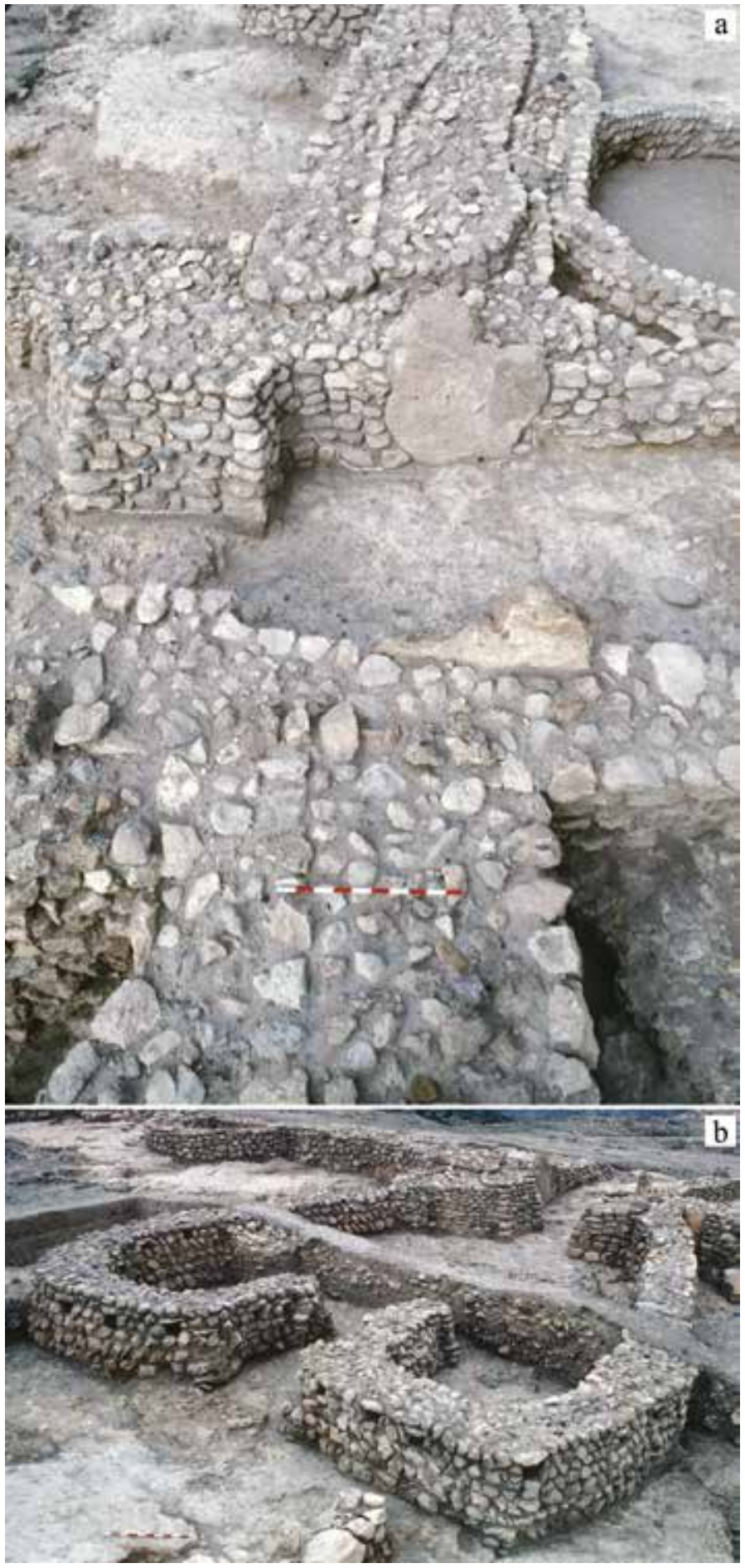

FIG. 4. Fotografías obtenidas durante las intervenciones realizadas en los años 80 en la entrada principal-CE6-de Los Millares: a) jambas ortostáticas; b) vista desde el exterior de la 'barbacana' con la estatua-menhir a la derecha. 
La incorporación de la estatua-menhir a la muralla pudo producirse a través de un traslado desde alguna parte del inmediato espacio de la necrópolis, posiblemente desde la parte de esta incorporada al interior del ampliado espacio doméstico definido por la Muralla I -Zona A- en 2900 cal вс. De hecho, la cota de apoyo de su cara inferior, a la altura de la primera hilada de cimentación de la propia muralla, implica que, incluso en el momento de la configuración inicial de la puerta, la estatua-menhir aparecería enterrada en su tercio inferior. En cualquier caso, el emplazamiento elegido no fue casual, sino que complementó el diseño simbólico del acceso principal al poblado hasta la construcción de la 'barbacana'.

\subsubsection{Descripción y paralelos}

Se trata de un bloque de caliche cuyas dimensiones son 2,03 $\mathrm{m}$ de altura y $0,78 \mathrm{~m}$ de anchura máxima, mientras su anchura media es de 0,70 $\mathrm{m}$ en su cara exterior (Fig. 5b). Como la mayoría del material constructivo de Los Millares procede de canteras situadas en las inmediaciones (Carrión et al., 1993: 303-304) $)^{3}$ que aprovecharon los afloramientos, en ciertas partes del yacimiento, de caliches y travertinos, originados por el flujo de aguas ricas en carbonato cálcico cuya precipitación y formación se vio favorecida por un clima cálido y húmedo (IGME, 1978b). Estos se ordenan sobre los conglomerados con cantos de distinto tamaño situados por encima de una matriz arcillo-arenosa de época pliocuaternaria cuyos espesores llegan a alcanzar hasta los $40 \mathrm{~m}$ (IGME, 1978a).

Nos encontramos con un bloque trabajado para darle tendencia antropomorfa, cuya parte superior apuntada representaría la cabeza. Por debajo, se sitúan dos protuberancias más o menos centradas en el tercio superior del soporte que podríamos interpretar como ojos o como senos. Si atendemos

3 También Haro, M.: La puesta en valor de yacimientos arqueológicos de la Prehistoria Reciente en el sur de la Península Ibérica. Tesis doctoral presentada en 2012 en la Univ. de Granada, pp. 94 y 213 (http://hdl.handle. net/10481/20198). a la primera interpretación, estos se encontrarían separados por una incisión, la más ancha y larga de todas, que podría representar la nariz. Si consideráramos estas protuberancias como senos, nos sugerirían una representación femenina, pudiendo quedar los ojos representados en otras dos pequeñas protuberancias localizadas en la parte superior del soporte. Este conjunto de rasgos (Fig. 5b) nos indica que estamos ante una verdadera estatua-menhir.

En la misma cara exterior de esta nos encontramos con un conjunto de incisiones en las que domina la línea recta, con diseños geométricos, sin apenas elementos que puedan indicar motivos claros. En la mayoría de los casos son incisiones verticales o bien oblicuas, de componente lineal, sin un orden aparente, aunque ocupan la totalidad de la superficie de la estatua-menhir. Seguidamente describimos los elementos más complejos, es decir, todos aquellos que van más allá de un trazo simple (Fig. 5c):

1) trazo en L invertida;

2) dos pequeños círculos asociados;

3) signo en Phi griega;

4) retícula de trazos verticales y horizontales;

5) elemento en cruz;

6) trazos en $Y$ invertida;

7) figura en forma de cayado, interpretado como pico;

8) serpentiforme;

9) serpentiformes, uno más pequeño y fino;

10) figura en cruz latina;

11) forma geométrica rectangular abierta en su base;

12) figura en aspa;

13) figura en cruz;

14) elemento en $T$ invertida $y$

15) trazo vertical con elemento elipsoidal en la parte superior.

La ausencia de superposiciones no permite identificar una estratigrafía relativa entre las diversas representaciones, por lo que podemos plantear que se daría una sola fase de grabados. Por otro lado, técnicamente nos encontramos ante el uso generalizado de incisiones estrechas poco profundas, ya que los motivos están realizados bien con un instrumento 
J. A. Cámara Serrano, A. Dorado Alejos, L. Spanedda et al. / La demarcación de los espacios de tránsito en Los Millares (Santa Fe de Mondújar, Almería) y su relación con el simbolismo megalítico

lítico muy aguzado - perforador de sílex-o más probablemente con un instrumento metálico -punzón u hoja de cuchillo- que dejó un surco en v. También hemos documentado una variante de esta técnica incisa, en la que el surco es más ancho y profundo, con engrosamiento del surco en la parte central de
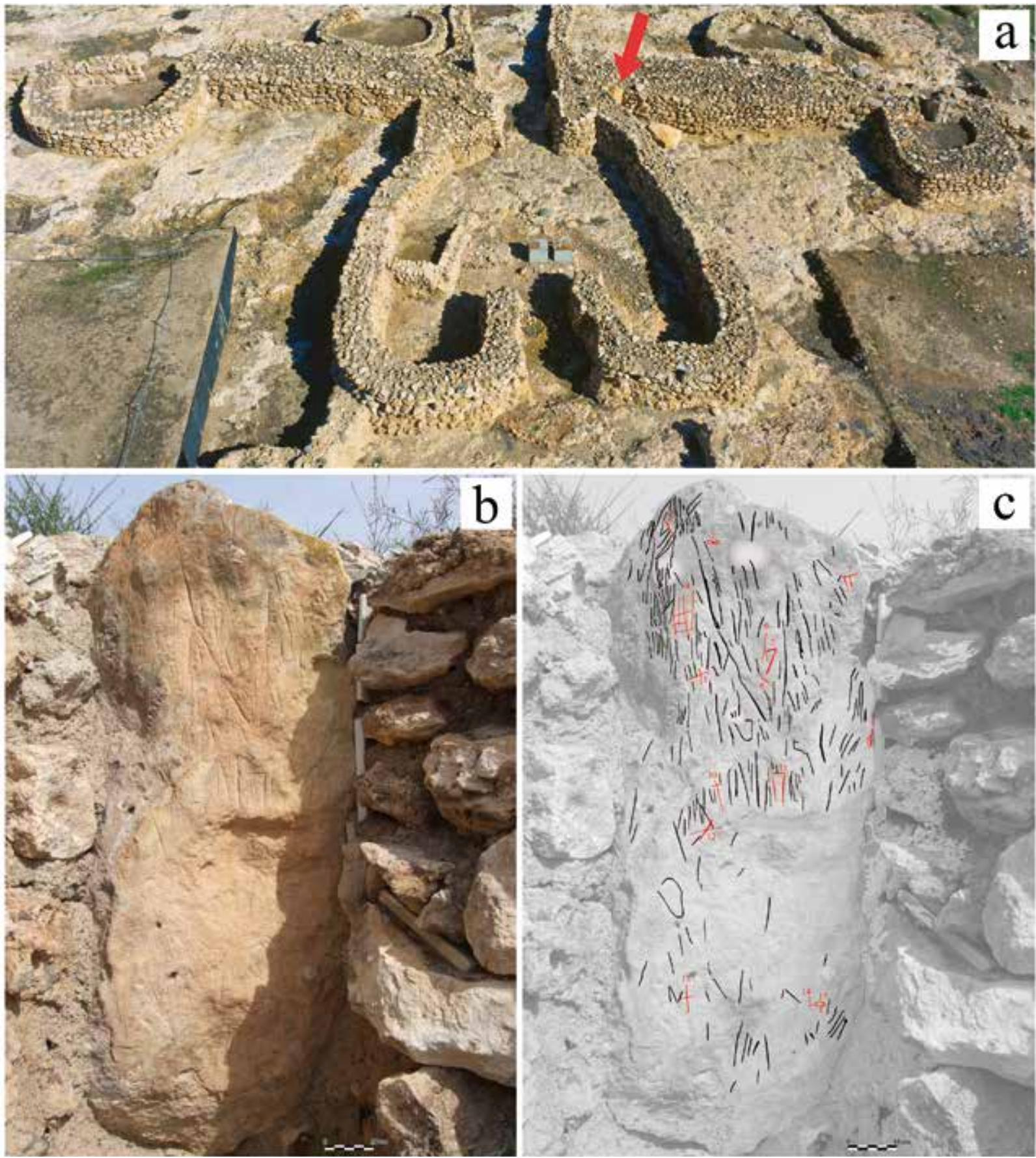

FIG. 5. Entrada principal de Los Millares en la actualidad y estatua-menhir: a) vista general del área del CE6; b) fotografía de detalle (modelo 3D: https://skfb.ly/oqSKn); c) interpretación de los motivos. 
cada trazo y una tendencia al perfil en U. Se puede plantear que una parte importante de los grabados fue ejecutada antes de que la estatua-menhir se colocara en el frente de la muralla, en el momento de su conformación y de su hipotético primer uso.

En las protuberancias mayores podemos observar que se ha perdido la costra calcárea que cubre la mayor parte del ortostato, un proceso erosivo causado por la exposición directa a los fenómenos atmosféricos y que ha afectado tanto al propio soporte como a los grabados, provocando fracturas y descamaciones. Dado que los derrumbes cubrieron la estatua-menhir hasta las excavaciones de los años 80 del s. Xx, se puede atribuir tal erosión a su periodo de uso, antes y después de su colocación junto a la puerta, sugiriendo que el revestimiento de la muralla no se extendió por la estatua-menhir que debió permanecer visible, contrastando con el resto de esta y con el cierre en madera del acceso.

Esta estatua-menhir se asemeja mucho a la reutilizada en el dolmen Fuente de La Corcha, Beas, Huelva (Vera et al., 2010: 123), en la que también podemos observar una decoración con líneas incisas, relativamente cortas, con diversas direcciones de trazado. A este caso podemos sumar la estela reutilizada en la galería del Toconal, Olvera, Cádiz (Rodríguez, 1990: 30-34; Hurtado, 2009: 70), de la que nos interesa referir, además de los ojos/senos, la representación de una posible arma, un aspecto que no hemos podido confirmar en el caso que nos ocupa y que hubiera sido trascendente en relación con su ubicación.

\subsection{Dos ortostatos decorados en el Sector norte de la Muralla I}

Incisiones se han documentado también en dos fragmentos de ortostatos colocados en la base del frente exterior de la torre CE32, en el extremo norte de la Muralla I (Fig. 3c). Están muy próximos entre sí, apenas a $60 \mathrm{~cm}$, separados solamente por otra piedra de menor tamaño (Fig. 6a) y decorados con líneas incisas (Fig. 6b).
Las incisiones deben ser anteriores a su reutilización como base de la torre (Fig. 7a) y, por tanto, los ortostatos pueden proceder también del contexto funerario invadido a partir del $2900 \mathrm{cal} \mathrm{BC}$ por la Muralla I.

\subsubsection{Descripción: Ortostato 1 y Ortostato 2}

Las dimensiones del Ortostato 1 son irregulares, alcanzando una anchura máxima de $0,75 \mathrm{~m}$ por una altura de $0,90 \mathrm{~m}$, no conociéndose su grosor al quedar oculto en el interior del muro (Fig. 7b). En su cara visible presenta treinta y nueve incisiones estrechas y poco profundas y una serie de pequeñas perforaciones, ocho en total, que se concentran en la parte superior del ortostato. Entre el conjunto de líneas solo observamos dos composiciones más complejas que las propias líneas incisas. Se trata de una figura en $\mathrm{T}$, con la barra superior un poco arqueada, y un pequeño zigzag (Fig. 7c). El resto de motivos grabados responde a líneas verticales $u$ oblicuas semejantes a las documentadas en la estatua-menhir descrita previamente.

El Ortostato 2, con dimensiones muy parecidas a las del anterior, presenta una anchura máxima de $1,10 \mathrm{~m}$ por una altura de $0,90 \mathrm{~m}$, quedando oculto su grosor en el interior del muro (Fig. 7d). En su superficie podemos observar doce incisiones estrechas y poco profundas, apenas perceptibles por estar afectadas por la acción erosiva de los diferentes agentes atmosféricos. Los grabados se localizan en la parte superior del ortostato y se resumen en una serie de trazos verticales, algunos con cierta inclinación, sin que hayamos identificado ningún motivo figurativo (Fig. 7e).

\section{Discusión: la estatua-menhir de la muralla de Los Millares y la simbología megalítica en el SE}

Como se ha dicho, la construcción de la línea de muralla más externa de Los Millares -Línea I- en torno a $2900 \mathrm{cal}$ BC propició que una parte de la necrópolis quedara incorporada al interior del recinto 
J. A. Cámara Serrano, A. Dorado Alejos, L. Spanedda et al. / La demarcación de los espacios de tránsito en Los Millares (Santa Fe de Mondújar, Almería) y su relación con el simbolismo megalítico

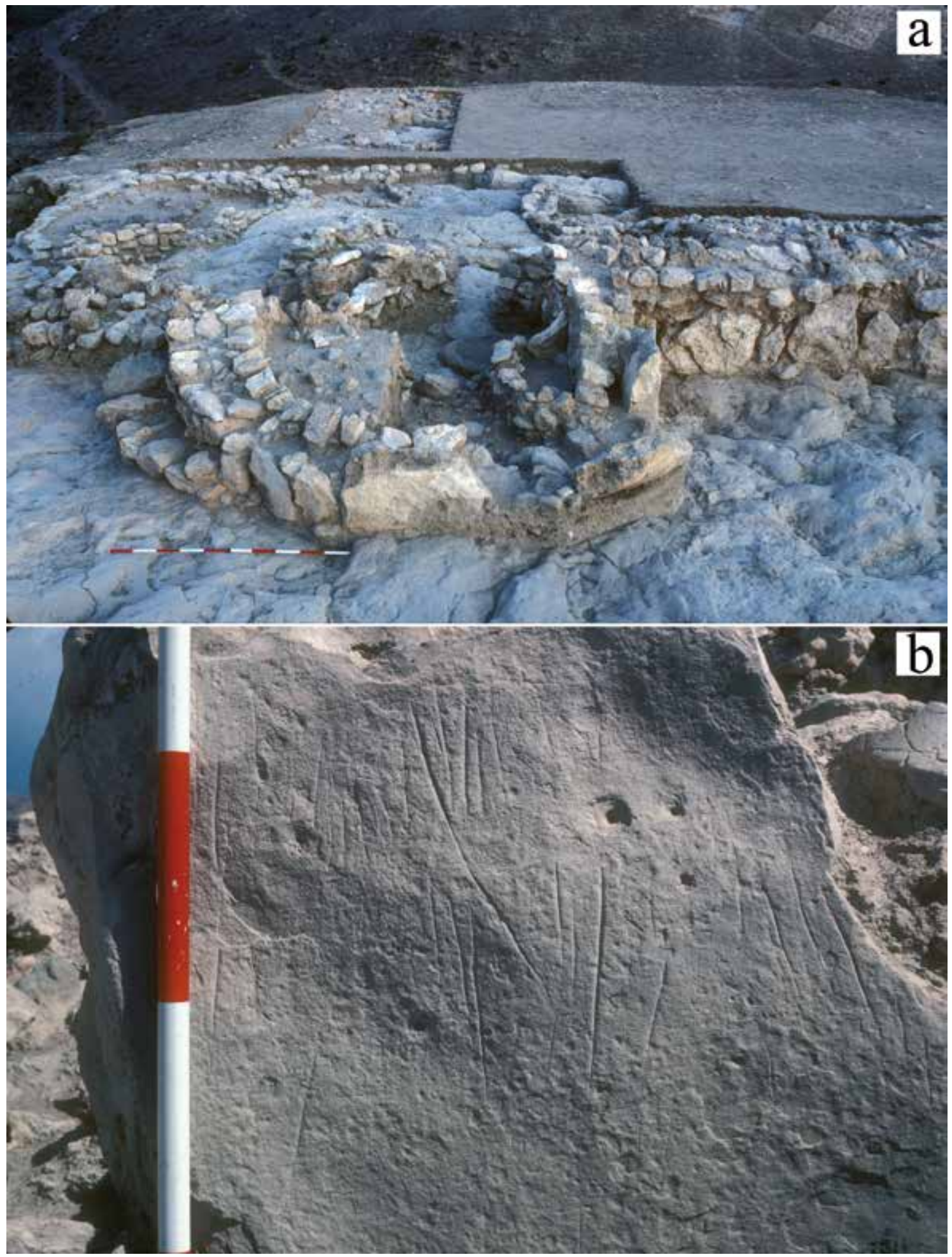

FIG. 6. La torre CE32 durante el proceso de excavación: a) vista exterior de la torre; b) detalle de uno de los dos ortostatos decorados localizados en la zona. 

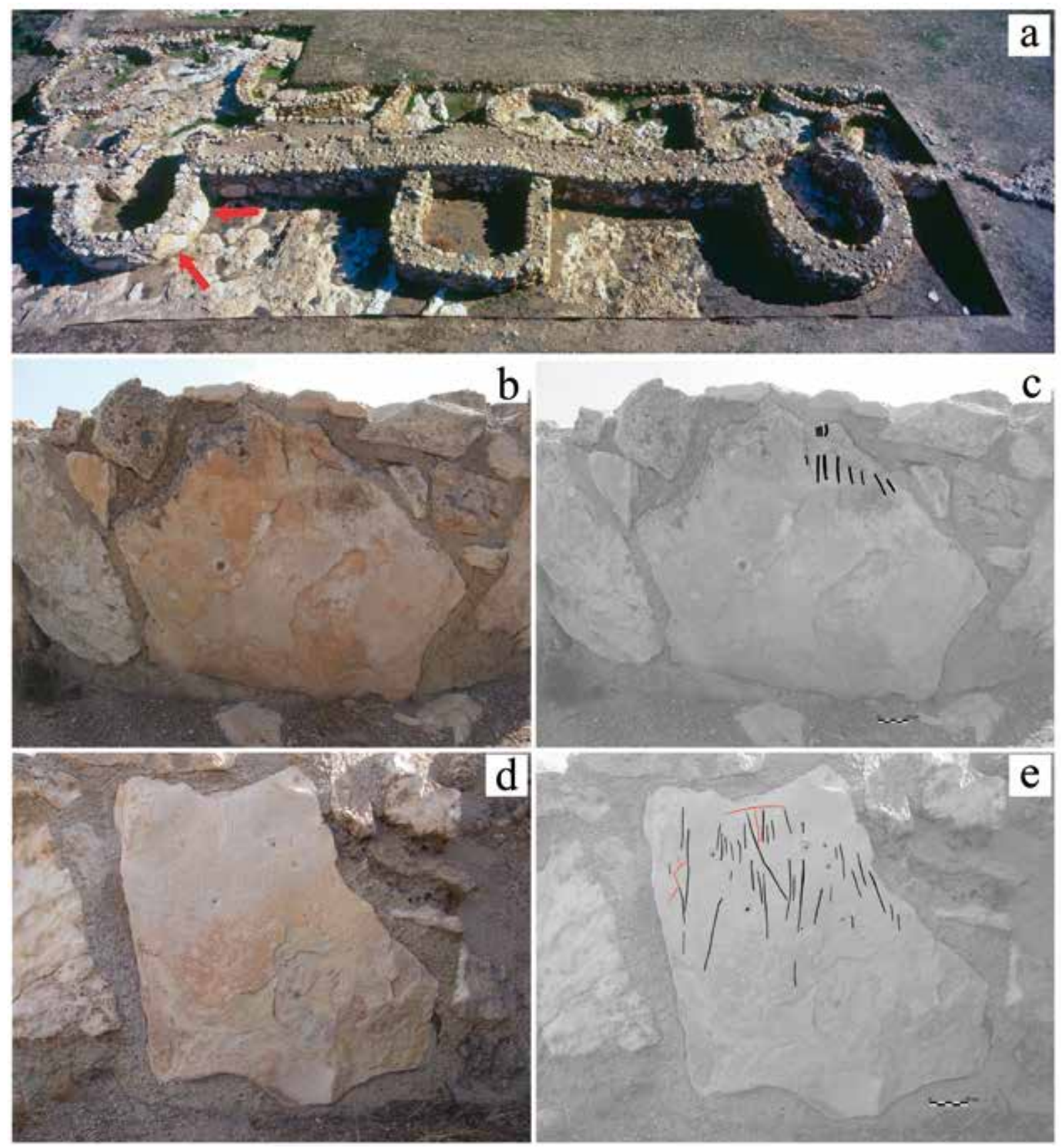

FIG. 7. La torre CE32 en la actualidad: a) localización de los ortostatos decorados; b) fotografia del ortostato 1-modelo 3D: https:// skfb.ly/oqSKA-; c) detalle de los motivos del ortostato 1; d) fotografia del ortostato 2 -modelo 3D: https://skfb.ly/oqSKt-; e) detalle de los motivos del ortostato 2 .

amurallado. Previamente el hábitat se extendía solo por la meseta más interna-Zonas в у с definidas por las Líneas II y III- y la terraza junto a la confluencia del río Andarax con la rambla de Huéchar
-Zona D, circundada por la Línea IV- (Molina y Cámara, 2005: 35; Molina et al., 2020a: 41).

Aunque la necrópolis siguió actuando como límite simbólico más exterior, el nuevo perímetro 
del poblado, la Muralla I, intensificó su función de confín 'sacralizado'. La inclusión de, al menos, dos tumbas -17 y 63- al interior del área de hábitat -Zona A- muestra, por una parte, el respeto por las áreas de reposo de los ancestros -al menos algunas de ellas- $y$, por otra, señala la profunda relación que en estas sociedades existía entre lo sagrado y lo profano, afectando el ritual a todas las esferas de la vida.

Se diluyó así una posible precedente oposición entre mundo de los vivos y mundo de los muertos pasando a estar integrados los ancestros -algunos-, y sus moradas, en la propia área de residencia de los vivos. No debió tratarse de un cambio radical pues elementos vinculados al ritual -cerámica simbólica, ídolos...- ya estaban presentes en contextos de hábitat $\mathrm{y}$, posiblemente, también determinadas reliquias eran mantenidas temporalmente en las viviendas.

Sin embargo, la 'reutilización' de elementos 'figurativos', sea en la puerta central, sea en el extremo norte de la muralla exterior, sí puede considerarse una 'innovación' ya que, por lo que sabemos hasta ahora del resto de las murallas calcolíticas del SE, la incorporación en ellas de representaciones no debió ser habitual.

Como se ha dicho, la estatua-menhir no es el único rasgo que aproxima la puerta central de Los Millares a la simbología presente en las tumbas megalíticas. Por un lado, las jambas ortostáticas y el pasillo que dirige al interior del poblado se refieren a la demarcación, más o menos sacralizada, del tránsito: hacia el interior del poblado, desde la 'ciudad' de los ancestros a la 'ciudad' de los vivos - pero no exclusivamente, como hemos dicho-. Se trata de una forma de clasificación que, referida habitualmente para los constreńimientos en los accesos a los sepulcros megalíticos (Thomas, 1990: 175-176; Chapman, 1991: 257-258), está implicada también en la propia segregación espacial que imponen las murallas concéntricas de Los Millares (Molina y Cámara, 2005: 38-41) y de la mayoría de los grandes asentamientos calcolíticos.

Por otra parte, la disposición de elementos simbólicos, más o menos íntegros o fragmentados, con fuerte vinculación a los ancestros que todavía

Ediciones Universidad de Salamanca / 요 residen en las tumbas cercanas, confiere a la Muralla I referentes simbólicos particulares.

En primer lugar, la estatua-menhir situada junto al acceso principal en torno a $2900 \mathrm{cal} \mathrm{BC}$ actúa, como las estatuas-menhir y estelas a la entrada de muchos megalitos (Bueno y Balbín, 2006: 44; Bueno et al., 2014: 10), como guardián del acceso y a la vez como referente de una legitimidad en la ocupación de un territorio particular, por parte de las comunidades que todavía ocupan Los Millares. La ocultación, casi total, de la estatua-menhir en el Cobre Reciente, tras la construcción de la 'barbacana', no debió suponer un cambio radical en estas concepciones. De hecho, las estrategias de uso del ritual funerario durante el Calcolítico se basan en la ocultación (Cámara et al., 2018: 39, 70) y no todas las representaciones de los ancestros se hallan en las entradas a los sepulcros (Bueno y Balbín, 2006: 44; Bueno et al., 2014: 10), existiendo abundantes casos en que incluso los propios ortostatos remiten a las imágenes de los ancestros e incluyen otras representaciones, grabadas o pintadas, sobre el propio soporte (Bueno y Balbín, 1996; Bueno et al., 2016: 371, 398; 2018: 248-252). También en los sepulcros de Los Millares se pueden apreciar estas articulaciones de representaciones al exterior, como los betilos, en los accesos, frecuentemente menhires, y en el interior, con la consideración de los elementos de sostén simbólicos como verdaderas estelas, así como el uso de grabados y pintura -o su combinación- para conformar motivos (Bueno et al., 2004: 55).

Ahora bien, las características de la estatua-menhir y de los elementos que la conforman evocan otras implicaciones. En primer lugar, los motivos en relieve, especialmente las protuberancias, conducen, obviamente, a la discusión sobre el sexo de la representación, femenino si consideramos las más destacadas como senos. De aceptarse que se tratase de una representación femenina, ello sería un argumento más a favor de la importancia de las mujeres entre los ancestros de consideración, como se ha sugerido a partir de la frecuente presencia de restos humanos femeninos en los sepulcros (Waterman y Thomas, 2011: 171-172; Cámara et al., 2016b: 
162-168). De hecho, la reproducción física, la fertilidad, como fuente de la futura fuerza de trabajo, es siempre un aspecto que se quiere propiciar y controlar (Martínez y López, 2020: 73, 80-81). Sin embargo, ya se ha seńalado en otros casos mediterráneos (Cámara y Spanedda, 2002: 385) la posibilidad de que nos encontremos ante la figuración de los ojos, un elemento ampliamente presente en las representaciones simbólicas de la Edad del Cobre del sur de la Península Ibérica (Hurtado, 2010: 139-181; Pascual, 2010: 81-111; Martínez y López, 2020: 71, 74-76, 80). Ninguno de los elementos representados se puede considerar claramente un arma o parte de un arma, algo que sería sugerente en relación con su vinculación a una muralla. Por el contrario, abundan los elementos que podrían formar parte de antropomorfos en la tradición esquemática del s de la Península Ibérica (Acosta, 1968) y ello podría vincular la estatua-menhir a los sistemas de representación de la genealogía que se han sugerido sobre distintos soportes en el s de la Península Ibérica (Martínez, 1988: 192; Lillios, 2008: 141169).

Tal vez algunos de estos trazos respondan a actividades vinculadas al uso $-\mathrm{y}$ afilado- simbólico de determinados útiles, como se ha sugerido en algunos casos (Edmonds, 1995: 62, 77; Cummings, 2017: 56, 226). Sin embargo, ello no invalidaría, en nuestra opinión, las argumentaciones aquí presentadas, dada además la relación de tales acciones con procesos de afirmación de la identidad (Taçon, 1991: 194-195, 204-205; Edmonds, 1995: 77) que pueden implicar también la deposición de armas en las inmediaciones y no solo su representación (Fábregas y Rodríguez, 2015: 55). En cualquier caso, esa posibilidad debería ser explorada con análisis traceológicos más detallados.

Sin duda, lo que podemos afirmar con mayor seguridad es que la representación de ciertos personajes, reales o imaginarios, tuvo una especial importancia en la demarcación del acceso principal del centro fortificado de Los Millares, al igual que esas representaciones fueron importantes en las tumbas para marcar la continuidad y la genealogía. En este sentido, no solo debemos resaltar la continuidad

Ediciones Universidad de Salamanca / 어요 implicada en la reutilización de elementos y motivos, como en otras áreas (Bueno et al., 2018: 244248), sino el hecho de que posiblemente estos, como los 'ídolos' muebles (Hurtado, 2010: 153175; Pascual, 2010: 110-111), tuvieron al parecer un carácter particular, propio y característico, dentro de la amplia tradición megalítica, como se revela en la ausencia de paralelos claros.

En segundo lugar, hay que referirse a los fragmentos de menhires o estatuas-menhir identificados en el extremo septentrional de la muralla exterior, en su límite junto a la caída hacia el río Andarax. Se trata de una de las pocas zonas en que se había referido una cimentación ciclópea de la muralla (Molina y Cámara, 2005: 36-37) que, dados estos hallazgos, no hay que excluir que estuviera conformada por restos reutilizados de estatuas-menhir. La incorporación de fragmentos de menhires en estructuras de cierre se había planteado en la Estremadura portuguesa (Gomes et al., 1985: 77-78), mientras es más frecuente la referencia a la reutilización de fragmentos de antiguos menhires en sepulcros más tardíos (Boujot y Cassen, 1993: 485-488; Kirk, 1993: 207-208; Mohen, 1993: 6), así como la reutilización de representaciones más completas en posiciones que pueden hacer pensar en su desplazamiento (Bueno et al., 2018: 248-252). La mayoría de estos procesos implican una transformación ideológica que, aun enfatizando la continuidad, manifiesta una cierta ruptura. Si estos fragmentos fueran los únicos ejemplos de soportes con figuraciones localizados en la muralla, y no contáramos con la estatua-menhir previamente referida, habría que pensar que la transformación que supuso la ampliación del espacio habitado en torno a 2900 cal BC fue más importante de lo que hasta ahora se había planteado, en cuanto a la relación con la situación precedente. En cualquier caso, también en el extremo septentrional del área defendida por la Muralla I -Zona A- permaneció en forma íntegra un exponente del antiguo carácter sacro-funerario de la zona, la Tumba 17. Ello nos sugiere que el reaprovechamiento, y apropiación, de símbolos en la construcción de la Muralla I, de hecho, en su base, fue una demostración intencional de sacralización 
de la nueva fundación, apoyada en la simbología ancestral -de forma metafórica y literal-.

Un problema adicional podría ser la discusión sobre el tipo de monumento al que previamente pertenecían estos ortostatos y su cronología. Se puede señalar, por un lado, que, como muestra la estatua-menhir en la puerta principal del poblado, es muy probable que estas piezas formaran parte también de estatuas-menhir a las que, incluso sin claras representaciones de armas, se les puede atribuir una cronología calcolítica, con una fecha de erección entre el 3200 y el 2900 cal BC, momento en el que el monumento o monumentos en cuestión fueron desmantelados para la inclusión de sus piezas en la muralla exterior. El hallazgo de ídolos muebles en las inmediaciones de la propia muralla (Arribas et al., 1981: 103), uno de ellos en la propia Torre CE32, refuerza las conexiones simbólicas entre los ancestros y la delimitación -del pobladoque aquí estamos refiriendo.

Finalmente, en el extremo meridional de la muralla exterior, la Tumba 63 fue incorporada al trazado de la propia muralla. Esta inclusión incide aún más en la demostración de la inclusión temprana, como miembros de pleno derecho de la formación social de Los Millares, de las comunidades que en las sierras de Alhama y Gádor se inhumaron en sepulcros ortostáticos y, especialmente, la asimilación de sus dirigentes, o determinados linajes, como parte de la élite de Los Millares. De hecho, la propia dispersión de los megalitos completa y complementa el control territorial del valle principal y sus afluentes (Molina y Cámara, 2005: 79-80). Además, en la Tumba 63 se localizó en posición horizontal una estela decorada en la que se aprecia, según la documentación de Leisner y Leisner (1943: 51, lám. 24.2), un serpentiforme y un seno/ ojo en relieve (Fig. 8) que claramente se relaciona con los presentes en la estatua-menhir del acceso. La importancia del mantenimiento de esta tumba y su representación interior tras $2900 \mathrm{cal} \mathrm{BC} \mathrm{pudo}$ ser aún mayor si el crecimiento del poblado en ese momento se debió a la concentración en él de parte de las poblaciones 'megalíticas' del entorno.

Estatuas-menhir, estela, fragmentos de posibles estatuas-menhir e ídolos muebles cubren así todo el trazado de la muralla exterior y certifican la defensa del poblado y la justificación de la propiedad del terreno circundante por la presencia en él de los ancestros en tiempos más o menos remotos. Entre
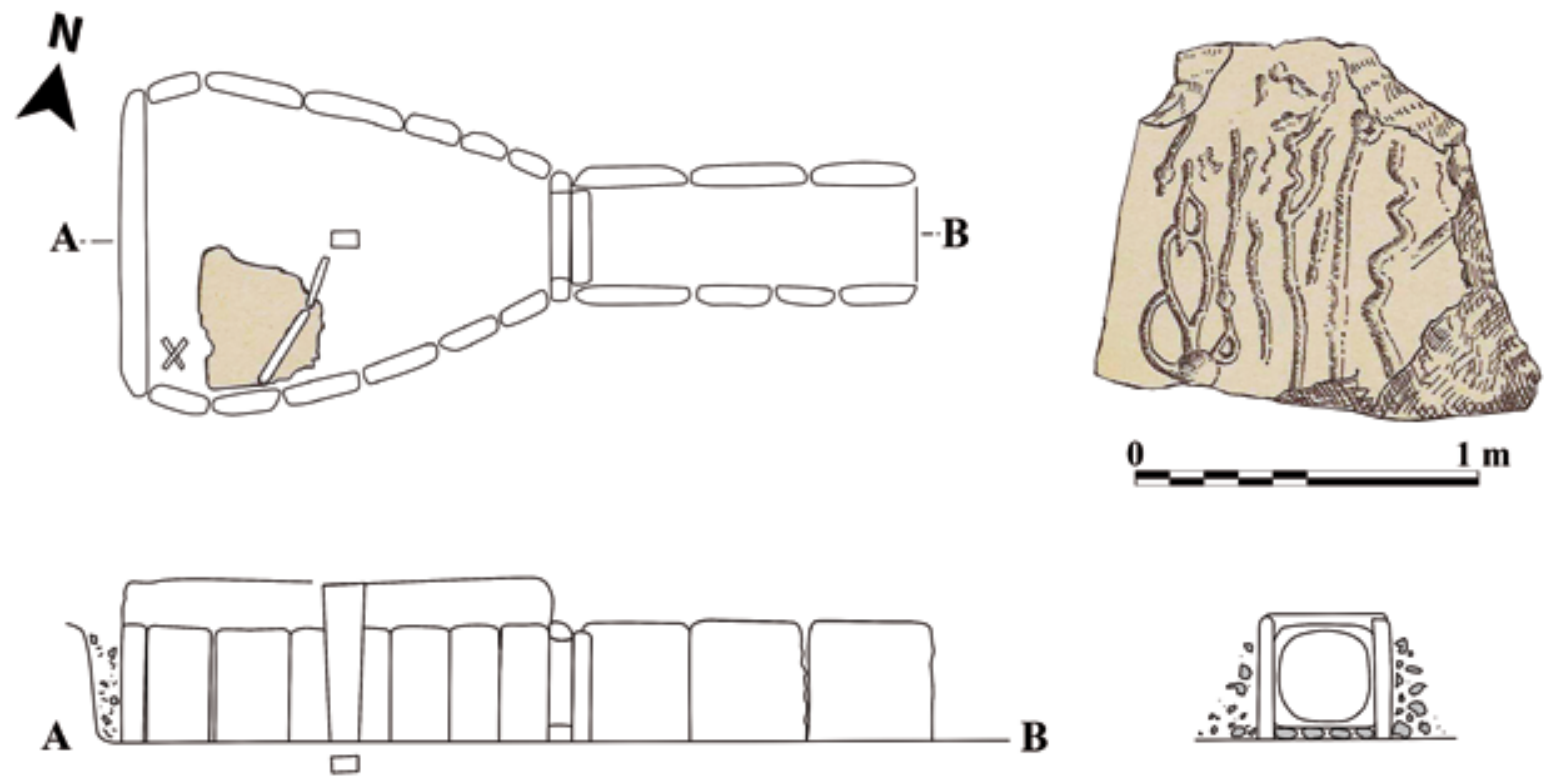

Fig. 8. Tumba 63 de Los Millares con su estela decorada (modificada a partir de Leisner y Leisner, 1943). 
estos ancestros se incluyen los de todos aquellos que decidieron formar parte de la misma unidad política en un momento determinado.

Además, la situación de la estela en la Tumba 63 recuerda otros casos conocidos en el SE, por ejemplo en las necrópolis de Gor y Fonelas (Leisner y Leisner, 1943: 92, lám. 35.6; Ferrer, 1976: 97-100), y sugiere una relación con los procesos de individualización y acentuación de la jerarquización social en los que, aun con la ocultación relativa de la desigualdad en las tumbas colectivas, se manifestaba la diferenciación al menos durante el desarrollo de determinados rituales, vinculando determinados individuos recientemente fallecidos, y sus familias, a los ancestros míticos (Cámara et al., 2018: 70-72).

\section{Valoración final}

Los diferentes elementos figurativos -fragmentos de menhires o de estatuas-menhir, estatua-menhir, estela e ídolos muebles- documentados en la muralla exterior -Línea I- del sistema defensivo de Los Millares deben relacionarse con el proceso de ampliación del poblado que tuvo lugar en torno a 2900 cal BC. Esta ampliación se concretó en la ocupación de parte de la antigua área de necrópolis -Zona A- más allá de la meseta central -Zonas в y C- en la que, junto con la ciudadela -Zona D-, se había concentrado previamente la población. Esta expansión supuso, por un lado, triplicar la superficie original del poblado, pero, por otro, englobó áreas de mayor pendiente y obligó a desmantelar, posiblemente, algunas de las estructuras de la necrópolis, aunque la Tumba 17 y la 63 quedaron dentro del nuevo recinto defensivo (Molina y Cámara, 2005: 55), implicando ahora una más profunda unión entre sagrado y profano.

Además de respetar al menos estos dos sepulcros -y los que quedaron al exterior del nuevo recinto-, se pasó a integrar, en diferentes partes del trazado de la muralla exterior, otros elementos simbólicos.

De la misma manera que los accesos a las tumbas, y a las cámaras, reciben una especial atención mostrando no solo el paso entre diferentes ámbitos

Ediciones Universidad de Salamanca / 요 -vida-muerte, tránsito-último destino-, sino también sistemas de clasificación -por el largo recorrido y la compartimentación-, la puerta principal de Los Millares se dotó de un aparato simbólico para marcar el tránsito, con jambas megalíticas y pasillo de acceso, y clasificar a las personas de una forma que ya se perseguía con la segmentación de las distintas murallas concéntricas. Este simbolismo no excluye, por supuesto, la esencial función defensiva del sistema (Cámara et al., 2016a: 96-97).

Además, también como sucede con menhires y betilos en numerosas tumbas, una estatua-menhir en la fachada, a la derecha de la puerta en este caso, actuó como referente a la legitimación por los ancestros de la identidad de los habitantes de Los Millares y la propiedad del entorno -frente a cualquier visitante o enemigo-. El incremento de los conflictos, con la realización de la 'barbacana', aun ocultando casi totalmente la estatua-menhir, no debió cancelar su significación, pues la ocultación al exterior de un hecho conocido sigue siendo útil a la transmisión del mensaje, como, por otra parte, se aprecia también en la ocultación de los muertos tras el funeral. De hecho, también en las tumbas, incluyendo la 63, la posición de las estelas se generaliza en los accesos a las cámaras o al interior de ellas, en su fondo, es decir, en un espacio oculto a la mayoría de las personas, aunque claramente relevante.

Se puede señalar que la ocultación y la legitimación por los ancestros van todavía más unidas a las otras figuraciones presentes en la muralla exterior de Los Millares. La fragmentación de menhires, o estatuas-menhir, para ser usados en la cimentación del extremo septentrional de la Muralla I conectaba de nuevo el pasado -antes de $2900 \mathrm{cal} \mathrm{вс-} \mathrm{al}$ presente de la construcción de la muralla -en torno a 2900 cal BC-, de la misma forma que la Tumba 17 , en las inmediaciones, hacía presente el mismo mensaje de continuidad, referido también por los ídolos muebles localizados en la zona (Arribas et al., 1981: 103).

Finalmente, en el extremo contrario, al SE, la Tumba 63, englobada en la muralla, y su estela interior, el único elemento de los aquí citados en relación con la muralla precedentemente conocido 
(Leisner y Leisner, 1943: lám. 24.2), no solo actuaban como referentes de las poblaciones asimiladas, cuya integración explicaría el crecimiento del poblado, sino de la justificación de esos procesos a través de la vinculación a ancestros de personas particulares, incluso élites de estas mismas poblaciones integradas. Los motivos en relieve de esta estela claramente la vinculan a la estatua-menhir localizada junto a la puerta principal.

En lo concreto, aunque todos los elementos están vinculados a la muralla, mientras la estatua-menhir, el único visible -hasta el Cobre Reciente de forma clara-, se relaciona con el acceso y la clasificación -no solo entre los residentes y los foráneos, sino también entre los propios habitantes según su zona de residencia-, la estela al interior de la Tumba 63 y los fragmentos reutilizados en el extremo norte están más relacionados con la demarcación de la exclusión del acceso por zonas no permitidas y a personas no conectadas a los ancestros fundadores o a los ancestros de los nuevos aliados. Los ídolos muebles de la zona norte (Arribas et al., 1981: 103), como los del Fortín 1 (Molina y Cámara, 2005: 75), pudieron conectar ambos significados: cohesión y clasificación a partir de los ancestros y demarcación de los límites por su concentración en estos espacios fortificados.

\section{Bibliografía}

Acosta, P. (1968): La pintura rupestre esquemática en España. Memorias del Seminario Prehistoria y Arqueología, 1. Salamanca.

Afonso, J. A.; Cámara, J. A.; Martínez, G. y MoliNA, F. (2011): "Objetos en materias primas exóticas y estructura jerárquica de las tumbas de la necrópolis de Los Millares (Santa Fe de Mondújar, Almería, España)". En García, L.; Scarre, C. y Wheatley, D. W. (eds.): Exploring Time and Matter in Prehistoric Monuments: Absolute Chronology and Rare Rocks in European Megaliths. Menga: Journal of Andalusian Prehistory, Monograph, 1. Sevilla: Junta de Andalucía, pp. 295-334.

Almagro, M. y Arribas, A. (1963): El poblado y la necrópolis megalitica de Los Millares (Santa Fe de
Mondújar, Almería). Biblioteca Praehistorica Hispanica, III. Madrid: CSIC.

Aranda, G.; Díaz-Zorita, M.; Hamilton, D.; Milesi, L. y SÁnchez, M. (2020): “The Radiocarbon Chronology and Temporality of the Megalithic Cemetery of Los Millares (Almería, Spain)”, Archaeological and Anthropological Sciences, 12 (104). https://doi. org/10.1007/s12520-020-01057-7

Arribas, A. y Molina, F. (1987): "New Bell Beaker Discoveries in the Southeast Iberian Peninsula". En Waldren, W. H. y Kennard, R. C. (eds.): Bell Beaker discoveries of the western Mediterranean. Definition, interpretation, theory and new site data. BAR Intern. Ser., 331. Oxford: Archaeopress, t. I, pp. 129-146.

Arribas, A.; Molina, F.; Carrión, F.; Contreras, F.; Martínez, G.; Ramos, A.; Sáez, L.; De la Torre, F.; Blanco, I. y Martínez, J. (1987): "Informe preliminar de los resultados obtenidos durante la vi Campańa de excavaciones en el poblado de Los Millares (Santa Fe de Mondújar, Almería, 1985)”. En Anuario Arqueológico de Andalucía 1985. Sevilla: Junta de Andalucía, t. II, pp. 245-262.

Arribas, A.; Molina, F.; Sáez, L.; De la Torre, F.; Aguayo, P. y Nájera, T. (1981): "Excavaciones en Los Millares (Santa Fe de Mondújar, Almería). Campaña de 1981", Cuadernos de Prehistoria de la Universidad de Granada, 6, pp. 91-121. https://doi. org/10.30827/cpag.v6i0.1182

Beck, J. (2016): "Part of the Family: Age, Identity, and Burial in Copper Age Iberia”. En Osterholtz, A. J. (ed.): Theoretical approaches to analysis and interpretation of commingled human remains. Springer International Publishing, pp. 47-73. https://doi. org/10.1007/978-3-319-22554-8_4

Blance, B. (1971): Die Anfänge der Metallurgieauf der Iberischen Halbinsel. SAM, 4. Berlin: Mann.

Boujot, C. y Cassen, S. (1993): "A pattern of evolution for the Neolithic funerary structures of the West of France", Antiquity, 67, pp. 477-491. https://doi. org/10.1017/S0003598X00045701

Bueno, P. y De Balbín, R. (1996): "La decoración del dolmen de Alberite”. En Ramos, J. y Giles, F. (eds.): El dolmen de Alberite (Villamartín). Aportaciones a las formas económicas y sociales de las comunidades neoliticas del Noroeste de Cádiz. Cádiz: Univ. de Cádiz, pp. 285-313.

Bueno, P. y De Balbín, R. (2006): "Between power and mythology. Evidence of social inequality and hierarchisation in Iberian megalithic art”. En DíAz DEL 
Río, P. y García, L. (eds.): Social Inequality in Iberian Late Prehistory. BAR Intern. Ser., 1525. Oxford: Archaeopress, pp. 37-52.

Bueno, P.; De Balbín, R. y Barroso, R. (2004): “Arte megalítico en Andalucía: una propuesta para su valoración global en el ámbito de las grafías de los conjuntos productores del Sur de Europa", Mainake, XXVI, pp. 29-62.

Bueno, P.; De Balbín, R. y Barroso, R. (2014): "Custodian Stones: Human Images in the Megalithism of the Southern Iberian Peninsula". En Cruz, A.; Cerrillo-Cuenca, E.; Bueno, P.; Caninas, J. C. y Batata, C. (eds.): Rendering Death-Ideological and Archaeological Speeches from Recent Prehistory (Iberia). BAR Intern. Ser., 2648. Oxford: Archaeopress, pp. 3-12.

Bueno, P.; De Balbín, R. y Barroso, R. (2015): “Human images, images of ancestors, identity images. The South of the Iberian Peninsula". En Rodríguez, G. y Marchesi, H. (dirs.): Statues-menhirs et pierres levees du Néolithique à aujourd'hui. Direction Régionale des Affaires Culturelles Languedoc-Roussillon, pp. 443-455.

Bueno, P.; De Balbín, R.; Barroso, R.; Carrera, F. y Hunt, M. A. (2016b): "El arte y la plástica en el tholos de Montelirio". En Fernández, A.; García, L. y Díaz-Zorita, M. (eds.): Montelirio: un gran monumento megalítico de la Edad del Cobre. Sevilla: Junta de Andalucía, pp. 365-405.

Bueno, P.; Linares, J. A.; De Balbín, R. y Barroso, R. (2018): Simbolos de la muerte en la Prehistoria Reciente del Sur de Europa. El dolmen de Soto, Huelva. España. Arqueología Monografías. Sevilla: Junta de Andalucía.

Calvín, M. E. (2014): "Estudio, análisis y valoración social de la necrópolis calcolítica de Los Millares (Santa Fe de Mondújar, Almería)", Arqueología y Territorio, 11, pp. 1-13. http://doi.org/10.5281/zenodo. 3775293

Cámara, J. A.; Afonso, J. A. y Molina, F. (2016a): “A Marxist Approach to Violence: Iberian Southeast in Late Prehistory". En García-Piquer, A. y VilaMitjà, A. (eds.): Beyond War: Archaeological Approaches to Violence. Cambridge: Cambridge Scholars Publishing, pp. 93-114.

Cámara, J. A.; SÁnchez, R.; Riquelme, J. A.; Martín, S.; Afonso, J. A.; Pau, C.; García, M. F.; Nicas, J.; Spanedda, L.; González, A.; Jiménez, S. A. y LAFFrANCHI, Z. (2016b): "Culte aux ancêtres dans la période chalcolithique de la péninsule ibérique? Le sacrifice d'animaux, la circulation des restes humains et la différence de traitement entre hommes et femmes dans les tombes du site archéologique à 'Marroquies' (Jaén, Espagne) trouvées dans les fouilles de la 'Tranche 3' du système du tramway", L'Anthropologie, 120, pp. 145-174. https://doi.org/10.1016/j. anthro.2016.03.002

Cámara, J. A. y Spanedda, L. (2002): “Decoración, representaciones figuradas y áreas rituales en la Prehistoria Reciente sarda: acumulación, control del territorio y jerarquización". En Waldren, W. H. y Ensenyat, J. A. (eds.): World Islands in Prehistory. International Insular Investigations. BAR Intern. Ser., 1095. Oxford: Archaeopress, pp. 373-394.

Cámara, J. A.; Spanedda, L. y Molina, F. (2018): "Exhibición y ocultación de las diferencias sociales en el ritual funerario calcolítico". En Espinar, M. (coord.): La muerte desde la Prehistoria a la Edad Moderna. Acción formativa de Doctorado Universidad de Granada. Libros ерссм Estudios, 23. Granada: Univ. de Granada, pp. 37-92.

Carrión, F.; Alonso, J. M.; Rull, E.; Castilla, J.; Ceprián, B.; Martínez, J. L. y Haro, M. (1993): "Los sistemas de aprovisionamiento por las comunidades prehistóricas del se de la Península Ibérica durante la Prehistoria Reciente". En Campos, J. M. y Nocete, F. (coords.): Investigaciones Arqueológicas en Andalucía. 1985-1992. Proyectos. Huelva: Junta de Andalucía, pp. 295-310.

Castro, P. V.; Escanilla, N.; Oltra, J.; Escoriza, T. y SARKIS, D. (2010): "Unlike Communities: Domestic Architectural Duality in Late Prehistory of the Western Mediterranean”. En Bettencourt, A. M. S.; Sanches, M. J.; Alves, L. B. y Fábregas, R. (eds.): Conceptualising Space and Place. On the role of agency, memory and identity in the construction of space from the Upper Palaeolithic to the Iron Age in Europe. BAR Intern. Ser., 2058. Oxford: Archaeopress, pp. 143-152.

Chapman, R. W. (1991): La formación de las sociedades complejas. La Peninsula Ibérica en el marco del Mediterráneo Occidental. Barcelona: Crítica.

Cosmas, J.; Itegaki, T.; Green, D. y Joseph, N. (2003): "Providing Multimedia Tools for Recording, Reconstruction, Visualisation and Database Storage”. En Arnold, D.; Chalmers, A. y NiccolucCI, F. (eds.): $4^{\text {th }}$ International Symposium on Virtual Reality, Archaeology and Intelligent Cultural Heritage VAST (2003). Brighton: Eurographic Association, pp. 165-174. 
Cummings, V. (2017): The Neolithic of Britain and Ireland. London: Routledge. https://doi. org/10.4324/9781315718866

Edmonds, M. (1995): Stone tools and society. Working stone in Neolithic and Bronze Age Britain. London: Routledge. https://doi.org/10.4324/9780203481080

EsCorizA, T. (1991-1992): "La formación social de Los Millares y las 'producciones simbólicas'”, Cuadernos de Prehistoria de la Univ. de Granada, 16-17, pp. 133-165. https://doi.org/10.30827/cpag.v16i0.1301

Esquivel, J. A. y Navas, E. (2007): “Geometric architectural pattern and constructive energy analysis at Los Millares Copper Age Settlement (Santa Fe de Mondújar, Almería, Andalusia)", Journal of Archaeological Science, 34, pp. 894-904. https://doi.org/10.1016/j. jas.2006.09.003

FÁbregas, R. y Rodríguez, C. (2012): “A Prehistoria Recente do Barbanza". En Fábregas, R. y Rodríguez, C. (eds.): A arte rupestre no Norte do Barbanza. Santiago de Compostela: Andavira Editora, pp. 61-84.

Ferrer, J. E. (1976): "La necrópolis megalítica de Fonelas (Granada). El sepulcro 'Moreno 3' y su estela funeraria", Cuadernos de Prehistoria de la Univ. de Granada, 1, pp. 75-109. https://doi.org/10.30827/ cpag.v1i0.711

Gilman, A. (1976): "Bronze Age dynamics in South-east Spain”, Dialectical Anthropology, 1 (4), pp. 307-319. http://www.jstor.org/stable/29789869

Gomes, R. V.; Gomes, M. V. y Dos Santos, M. F. (1983-84): "Santuário exterior e povoado calcolítico do Escoural”, Clio/Arqueología, 1, pp. 77-78.

Haro, M.; Carrión, F. y García, D. (2006): “Territorio y georrecursos en el Cabo de Gata (Níjar, Almería) durante la Edad del Cobre". En Martínez, G.; Morgado, A. y Afonso, J. A. (coords.): Sociedades prehistóricas, recursos abióticos y territorio. Granada: Fund. Ibn al-Jatib/Ayto. de Loja, pp. 315-326.

Hurtado, V. (2009): “Cádiz”. En García, L. y Ruiz, B. (coords.): Las grandes piedras de la Prehistoria. Sitios y Paisajes Megaliticos de Andalucía. Antequera: Junta de Andalucía, pp. 55-87.

Hurtado, V. (2010): "Representaciones simbólicas, sitios, contextos e identidades territoriales en el Suroeste Peninsular”. En Cacho, C.; Maicas, R.; GALÁn, E. y Martos, J. A. (coords.): Ojos que nunca se cierran. Ídolos en las primeras sociedades campesinas. Madrid: MAN, pp. 137-198.

IGME (1978a): Mapa Geológico de España, 1:50.000, Hoja $n{ }^{\circ} 1044$ Alhama de Almería.
IGME (1978b): Mapa Geológico de España, 1:50.000, Hoja n. ${ }^{\circ} 1045$ Almería.

KIrk, T. (1993): "Space, subjectivity, power and hegemony: megaliths and long mounds in Earlier Neolithic Brittany". In Tilley, C. (ed.): Interpretative Archaeology. Explorations in Anthropology Series. Exeter: Berg, pp. 181-223.

Leisner, G. y LeIsner, V. (1943): Die Megalithgräber der Iberischen Halbinsel. Der Süden. Römisch-Germanische Forschungen, 17. Berlin.

Lillios, K. T. (2008): Heraldry for the Dead. Memory, Identity and the Engraved Stone Plaques of Neolithic Iberia. Austin: UTP.

Lull, V.; Micó, R.; Rihuete, C. y Risch, R. (2010): "Límites históricos y limitaciones del conocimiento arqueológico: la transición entre los grupos arqueológicos de Los Millares y El Argar”. En Bueno, P.; Gilman, A.; Martín, C. y Sánchez-Palencia, F. J. (eds.): Arqueología, sociedad, territorio y paisaje. Estudios sobre Prehistoria Reciente, Protohistoria y transición al Mundo Romano en homenaje a $M$. D. Fernández-Posse. Bibliotheca Praehistorica Hispana, xxviII. Madrid: csic, pp. 75-94.

Martínez, G. y Afonso, J. A. (2003): "Formas de disolución de los sistemas sociales comunitarios en la Prehistoria Reciente del sur de la Península Ibérica”, Revista Atlántica-Mediterránea de Prehistoria y Arqueología Social, 6, pp. 83-114. https://revistas.uca. es/index.php/rampas/article/view/1418

Martínez, G. y López, V. (2020): “Representaciones simbólicas, desigualdades sociales e ideología de las sociedades del Neolítico Reciente y del Calcolítico de Andalucía oriental". En Bueno, P. y Soler, J. A. (eds.): Ídolos. Miradas milenarias. Alicante: MARQ, pp. 265-288.

Martínez, J. (1988): “Análisis de un sistema de parentesco en las pinturas rupestres de la Cueva de los Letreros (Vélez-Blanco, Almería)", Ars Praehistorica, 7, pp. 183-193.

McCarthy, J. (2014): "Multi-Image Photogrammetry as a Practical Tool for Cultural Heritage Survey and Community Engagement", Journal of Archaeological Science, 43, pp. 175-185. https://doi.org/10.1016/j. jas.2014.01.010

Mohen, J. P. (1993) : "Idoles mégalithiques", Revue des Études Anciennes, 95(1), pp. 5-10.

Molina, F.; Afonso, J. A.; Cámara, J. A.; Dorado, A.; Martínez, R. M. y Spanedda, L. (2020a): "The Chronology of Los Millares Site Defensive Systems (Santa Fe de Mondújar, Almería, Spain)”. En 
Delfino, D.; Coimbra, F.; Cardoso, D. y Cruz, G. (eds.): Late Prehistoric Fortifications in Europe: Defensive, symbolic and territorial aspects from the Chalcolithic to the Iron Age. Oxford: Archaeopress, pp. 31-43.

Molina, F. y Cámara, J. A. (2005): Guía del yacimiento arqueológico Los Millares. Sevilla: Junta de Andalucía.

Molina, F.; Cámara, J. A.; Afonso, J. A. y Spanedda, L. (2016): "Innovación y tradición en la Prehistoria Reciente del Sudeste de la Península Ibérica y la Alta Andalucía (c. 5500-2000 cal aC)". En Sousa, A. C.; Carvalho, A. y Veigas, C. (eds.): Terra e água. Escolher sementes, invocar a deusa. Estudos em Homenagem a Victor A. Gonçalves. Estudos \& Memórias, 9. Lisboa: Univ. do Lisboa, pp. 317-339.

Molina, F.; Mederos, A.; Delgado, A.; Cámara, J. A.; Peña, V.; Martínez, R. M.; Esquivel, F. J.; Granados, A.; Jiménez, S. A. y Esquivel, J. A. (2020b): "La necrópolis calcolítica de Los Millares: dataciones radiocarbónicas y valoración de la dieta y del medio ambiente a partir del análisis de isótopos estables", Trabajos de Prehistoria, 77 (1), pp. 67-86. https:// doi.org/10.3989/tp.2020.12247

Navas, E.; Esquivel, J. A. y Molina, F. (2008): "Butchering Patterns and Spatial Distribution of Faunal Animal Remains Consumed at the Los Millares Chalcolithic Settlement (Santa Fe de Mondújar, Almería, Spain)", Oxford Journal of Archaeology, 27 (3), pp. 325-339. https://doi.org/10.1111/j.14680092.2008.00311.x

PAscual, J. L. (2010): "Ídolos oculados sobre huesos largos en las cuencas del Júcar y del Segura". En СACHO, C.; Maicas, R.; Galán, E. y Martos, J. A. (coords.): Ojos que nunca se cierran. Ídolos en las primeras sociedades campesinas. Madrid: MAN, pp. 79-114.

Peña, V. (2011): "Excavando huesos en los museos. El caso de la necrópolis de 'Los Millares". En GonzÁlez, A.; Cambra-Moo, O.; Rascón, J.; Campo, M.; Robledo, M.; Labajo, E. y Sánchez, J. A. (eds.): Paleopatología: ciencia multidisciplinar. Madrid: Sociedad Española de Paleopatología, pp. 73-80.

Remondino, F. (2014): "Photogrammetry-basic theory”. En Remondio, F. y Campana, S. (eds.): $3 D$ recording and modeling in archaeology and cultural heritage: theory and best practices. Oxford: Archaeopress, pp. 7-12.

RodríGuez, R. (1990): "El arte grabado megalítico en la provincia de Cádiz: Galería cubierta 'El Toconal I' (Olvera, Cádiz)”, Gades, 19, pp. 25-40.

Shee, E. (1981): The Megalithic Art of Western Europe. Oxford.

Siret, L. (1893): "L’Espagne préhistorique", Revue des Questions Scientifiques, xxxIv, pp. 537-560.

Siret, L. (1907 [reed. 1994]): Orientales y occidentales en España en los tiempos prehistóricos. Colección L. Siret de Arqueología, 1. Almería.

Spanedda, L.; Alcaraz, F. M.; Cámara, J. A.; Molina, F. y Montufo, A. M. (2015): “Demografía y control del territorio entre el Iv y el III milenios ac en el Pasillo de Tabernas (Almería, España)". En GonçAlves, V. S.; Diniz, M. y Sousa, A. C. (eds.): Actas V Congresso do Neolítico Peninsular. Estudos \& Memórias, 8. Lisboa: Univ. de Lisboa, pp. 359-368.

Taçon, P. S. C. (1991): “The power of stone: Symbolic aspects of stone use and tool development in western Arnhem Land, Australia”, Antiquity, 65, pp. 192207. https://doi.org/10.1017/S0003598X00079655

Thomas, J. (1990): "Monuments from the inside: the case of Irish megalithic tombs", World Archaeology, 22 (2), pp. 168-178. https://doi.org/10.1080/00438 243.1990.9980138

Vera, J. C.; Linares, J. A.; Martín, D.; Camalich, M. D. y González, P. (2010): "Los inicios de la producción de alimentos en Huelva. Pasado y presente". En Gibaja, J. F. y Carvalho, A. F. (eds.): Os últimos caçadores-recolectores $e$ as primeiras comunidades produtoras do sul da Península Ibérica e do norte de Marrocos. Promontoria Monográfica, 15. Faro: Univ. de Algarve, pp. 119-129.

Waterman, A. J. y Thomas, J. T. (2011): "When the bough breaks: childhood mortality and burial practice in Late Neolithic Atlantic Europe", Oxford Journal of Archaeology, 30 (2), pp. 165-183. https://doi. org/10.1111/j.1468-0092.2011.00363.x 